\title{
Influence of Sn Addition on Castability, Mechanical Properties and Corrosion Resistance of JIS CAC804 Silzin Bronze Castings ${ }^{* 1}$
}

\author{
Yoshiyuki Goto ${ }^{* 2}$, Shinji Tanaka and Keiichiro Oishi \\ Research \& Development Dept., Sambo Plant, Mitsubishi Shindoh Co.,Ltd, Sakai 590-0906, Japan
}

In this study, we investigated the influence of addition of tin on JIS CAC804 properties. When tin is added, solidus and liquidus temperature of the alloy lower, and the solidification temperature range widens. Generally, if an alloy's solidification temperature range is wide, its castability is low, but not much castability difference was observed between CAC804 containing tin and that without.

A large portion of added tin is distributed in $\gamma$ phases in the form of solid solution, causing ductility to decline. Although results of erosion-corrosion resistance test differ depending on the test conditions, it is clear from the results of the tests we performed using two different solutions that tin has a function of alleviating weight loss in JIS CAC804. [doi:10.2320/matertrans.F-M2017817]

(Received December 22, 2016; Accepted April 6, 2017; Published June 25, 2017)

Keywords: lead free cutting copper alloy, copper-zinc-lead alloy, copper-zinc-silicon alloy, $\gamma$ phase, erosion-corrosion

\section{Introduction}

Recently, restriction on the use of lead, which is a hazardous substance, in copper-based alloys used for water faucets and other drinking water-related components is becoming tighter all around the world including Japan due to revisions in water quality standards. ${ }^{1)}$ In addition, such restriction is affecting the Restriction of Hazardous Substances Directive on electrical and electronic equipment ${ }^{2)}$ and the End-of Life Vehicles Directive on automotive products ${ }^{3)}$.

To cope with this trend, bismuth or silicon-containing leadfree copper-based alloys have been developed and are being used as substitute materials for JIS CAC406, a kind of bronze for casting, which has been used widely from the past. JIS CAC804, a lead-free copper-based alloy containing silicon (silicon bronze for casting), has excellent corrosion resistance, mechanical properties, and castability, ${ }^{4)}$ and therefore is used in various products such as water meters, valves, water joints, sprinkler components, and fire hydrants. CAC804 has characteristics including excellent dezincification corrosion resistance and stress corrosion cracking resistance. However, as components made of copper alloy are to be used in various environments, their erosion-corrosion resistance should also be considered.

We have found that to further enhance corrosion resistance of CAC804, adding tin is effective. The following are our research findings as to the effects of tin on CAC804.

\section{Test Method}

\subsection{Preparation of test materials and chemical composi- tions}

An ingot of CAC804 was melted in a high-frequency induction furnace then cast in molds after addition of an appropriate amount of tin as necessary in order to obtain test materials for measuring melting point and evaluating castability, mechanical properties, and corrosion resistance.

\footnotetext{
${ }^{* 1}$ This Paper was Originally Published in Japanese in J. JFS 87 (2015) 844-848.

${ }^{* 2}$ Corresponding author, E-mail: gotouy@mitsubishi-shindoh.co.jp
}

Chemical compositions of the test materials are shown in Table 1.

\subsection{Measurement of liquidus and solidus temperature}

Samples for measuring liquidus and solidus temperature were taken from the cast materials containing 0.47 to 0.57 mass $\%$ of tin or no tin then put to thermal analysis using Thermo Plus, a differential scanning calorimeter (hereinafter referred to as "DSC") manufactured by Rigaku Corporation. To find out solidus and liquidus temperatures, the samples were heated in the furnace of the apparatus filled with argon gas and set to record temperature between $20^{\circ} \mathrm{C}$ and $1100^{\circ} \mathrm{C}$ with a heating rate at $20^{\circ} \mathrm{C} / \mathrm{min}$. The solidus and liquidus temperatures were read from the line graph created by the DSC based on the recorded temperatures.

The temperatures recorded by the DSC and used to create a line graph is higher than the actual temperature of the alloy sample placed in the furnace because the DSC records the temperatures of the atmosphere in the furnace, and the temperature of the alloy sample reaches the atmospheric temperature slightly afterwards.

Table 1 Chemical composition (mass\%).

\begin{tabular}{|c|c|c|c|c|c|c|}
\hline & $\mathrm{Cu}$ & $\mathrm{Zn}$ & $\mathrm{Si}$ & $\mathrm{P}$ & $\mathrm{Sn}$ & other \\
\hline DSC samples & $75.2-77.5$ & Bal. & $2.8-3.2$ & 0.08 const. & $0.47-0.57$ & - \\
\hline \multirow{3}{*}{$\begin{array}{l}\text { Tatur mold } \\
\text { samples }\end{array}$} & 76.0 & Bal. & 3.0 & 0.08 & - & - \\
\hline & 76.2 & Bal. & 3.0 & 0.08 & 0.5 & - \\
\hline & 76.3 & Bal. & 2.9 & 0.08 & 0.5 & Zr:0.003 \\
\hline \multirow{4}{*}{$\begin{array}{l}\text { Metallographic } \\
\text { observation } \\
\text { samples }\end{array}$} & 75.7 & Bal. & 3.0 & 0.08 & - & - \\
\hline & 76.0 & Bal. & 3.0 & 0.09 & 0.2 & - \\
\hline & 75.9 & Bal. & 3.1 & 0.09 & 0.4 & - \\
\hline & 75.9 & Bal. & 3.1 & 0.08 & 0.7 & - \\
\hline $\begin{array}{c}\text { Tensile test } \\
\text { samples }\end{array}$ & $74.8-77.9$ & Bal. & $2.8-3.3$ & 0.08 const. & $0-0.54$ & - \\
\hline \multirow{3}{*}{$\begin{array}{l}\text { Erosion- } \\
\text { corrosion test } \\
\text { samples }\end{array}$} & 76.0 & Bal. & 3.0 & 0.08 & - & - \\
\hline & 76.2 & Bal. & 3.0 & 0.08 & 0.5 & - \\
\hline & 85.1 & Bal. & - & 0.02 & 4.8 & $\mathrm{~Pb}: 5.1$ \\
\hline
\end{tabular}




\subsection{Castability testing}

Each of the molten test materials having the compositions specified in the "Tatur mold samples" section of Table 1 was poured into a Tatur mold, and condition of the surface of the pipe-like shrinkage cavity generated at the center of the casting, and the porosities in the vicinity of the cavity surface were observed.

\subsection{Mechanical properties testing}

To obtain tensile test samples, materials containing 0.08 mass \% of phosphorus and various amounts of copper, zinc, silicon, and tin were melted in a high-frequency induction furnace. Each material was then poured into a shell mold for creating "No. A Specimen" specified in JIS H5120) while the material was at $1100 \pm 10^{\circ} \mathrm{C}$.

\subsection{Erosion-corrosion resistance testing}

A jet-in-slit test apparatus was used to evaluate erosion-corrosion resistance. Figure 1 shows the external appearance of the apparatus and its dimensions. Two different solutions were used for this test, and over the entire test duration, the solutions' temperature and flow speed at the outlet of the nozzle were fixed to be $40 \pm 2^{\circ} \mathrm{C}$ and $9.2 \mathrm{~m} / \mathrm{sec}$. respectively. Test duration was maximum one month. Each material's erosion-corrosion resistance was evaluated based on the amount of weight reduced over time.

One of the test solutions was a $3 \%$ saline solution, a mixture of tap water and natrium chloride (hereinafter referred to as " $\mathrm{NaCl}$ solution"), and the other was a solution prepared by adding sodium hypochlorite and sodium carbonate to tap water with residual chlorine concentration adjusted to $40 \mathrm{ppm} \pm$ $10 \mathrm{ppm}$, and $\mathrm{pH}$ adjusted to $6.5 \pm 0.2$ (hereinafter referred to as "hypochlorite water"). To prepare test samples, the shell mold for "No. A Specimen" was used.

\section{Results and Discussions}

\subsection{Melting point}

The relationship between zinc equivalent and the solidus temperature is shown in Fig. 2, and that between zinc equivalent and the liquidus temperature is shown in Fig. 3.

In both alloys, the solidus temperature increased as zinc

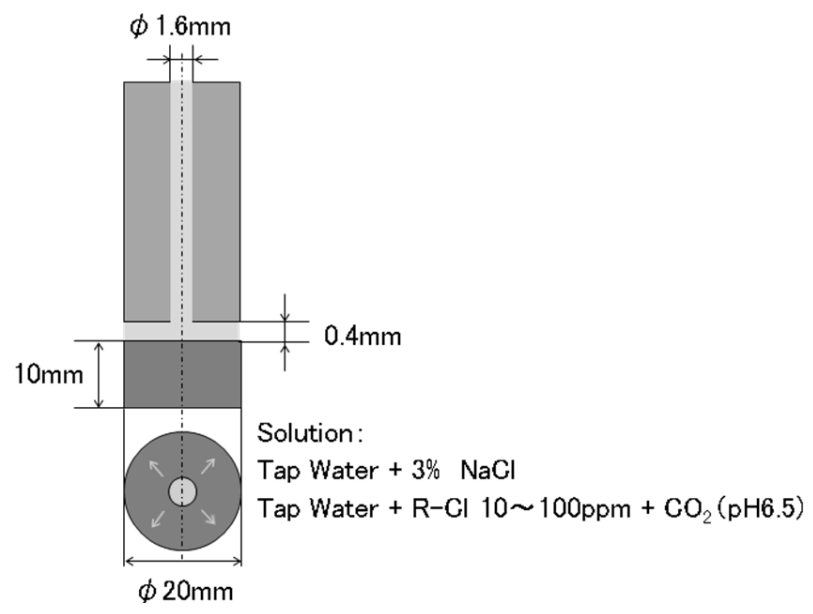

Fig. 1 Jet-in-slit testing apparatus. equivalent became larger, and the solidus temperature of the alloy containing 0.5 mass $\%$ of tin was lower than that of the tin-free alloy. Conversely, the liquidus temperature decreased as zinc equivalent became larger. Although the results varied, when compared at the same zinc equivalent level, the solidus temperature decreased by about $18^{\circ} \mathrm{C}$ and the liquidus temperature decreased by about $10^{\circ} \mathrm{C}$ as a result of adding 0.5 mass $\%$ of tin. In other words, solidification temperature range broadened by about $8^{\circ} \mathrm{C}$ due to the presence of 0.5 mass $\%$ of tin.

Just for information, Zinc equivalent indicates the effect of a third element added to a copper-zinc alloy on the alloy's metal structure. It is applicable to two-phase alloys (alloys having $\alpha$ and $\beta$ phases) but is not to CAC804 since CAC804 is a three-phase alloy containing $\alpha, \kappa$, and $\gamma$ phases. In the zinc equivalent calculation formula, coefficients applied to silicon and tin were 10 and 1 respectively. ${ }^{5)}$

\subsection{Castability}

Figure 4 shows the results of the sectional penetration flaw detection test performed on Tatur mold castings made of CAC804, CAC804 to which 0.5 mass $\%$ of tin was added (hereinafter referred to as " $0.5 \%$ Sn-CAC 804 "), and $0.5 \%$ SnCAC804 with a tiny amount of zirconium further added in

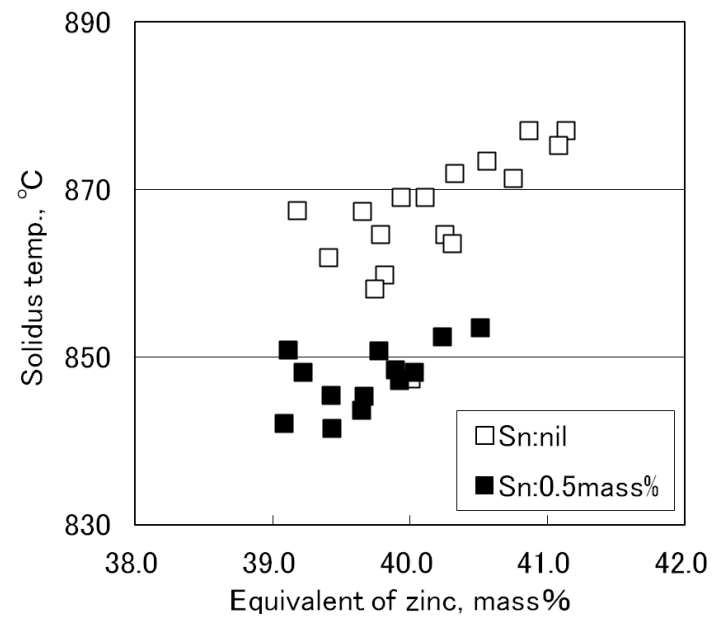

Fig. 2 Relationship between zinc equivalent and solidus temperature.

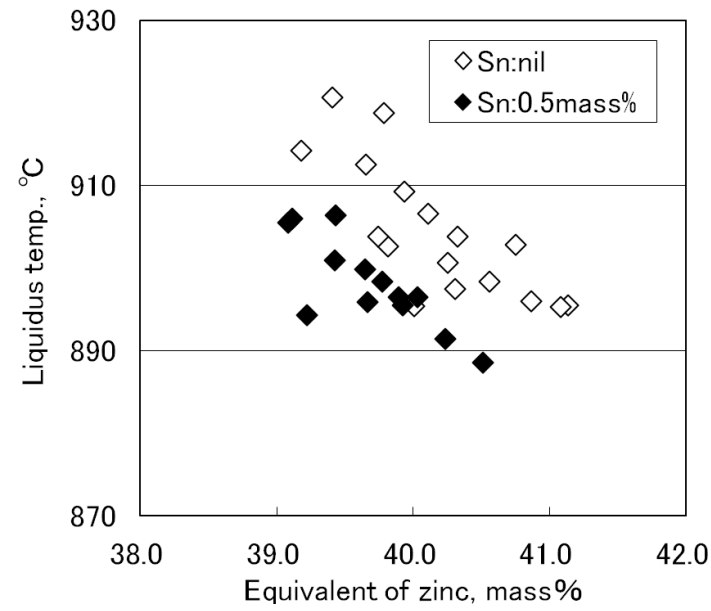

Fig. 3 Relationship between zinc equivalent and liquidus temperature. 
order to refine the metal structure of the alloy. 6,7$)$

Regardless of the presence of tin, porosities were only observed around the part that solidified last. A large number of porosities were found around the finally solidified part of the $0.5 \%$ Sn-CAC804 casting, but there were much less in the same location of the casting whose metal structure was refined by the effect of zirconium added.

Figure 5 shows a cross-sectional microstructure around the finally solidified part. Dendrites were observed in the $0.5 \%$
Sn-CAC804 casting, and there were large voids around them. In the casting having refined, granular structure, however, no dendrites were found. Voids were only found in the vicinity of the inner surface of the shrinkage cavity, and the size of the voids was small. With the dendrites gone, supply of molten metal was not hindered during solidification shrinkage, leading to a reduction in the number of such voids being left unfilled.

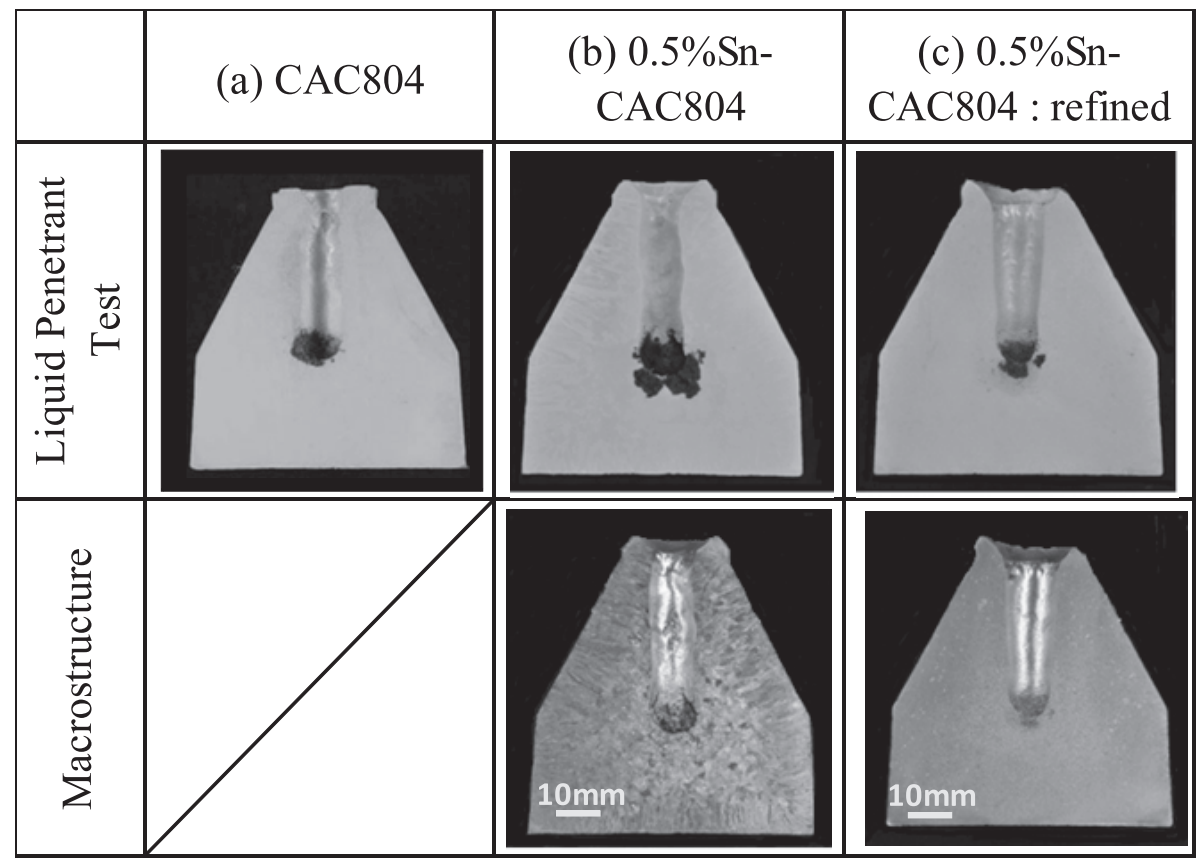

Fig. 4 Castability evaluation by Tatur mold Testing.

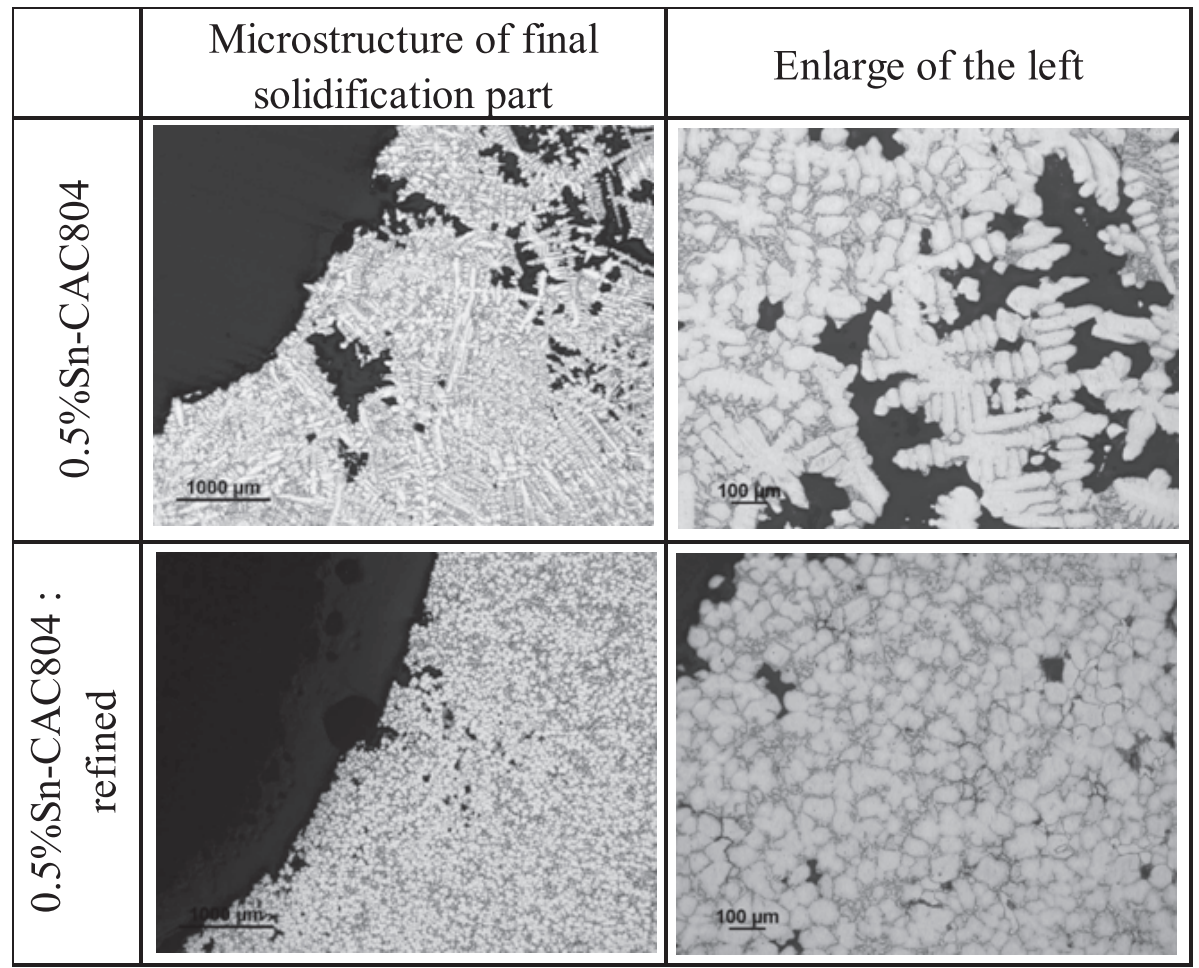

Fig. 5 Microstructure of finally solidified part. 


\subsection{Microstructure}

A piece of sound part around the finally solidified portion was taken from the $0.5 \%$ Sn-CAC804 Tatur mold casting and subjected to surface analysis using EPMA-8200 manufactured by JEOL Ltd. The results of the analysis are shown in Fig. 6. CAC804 contains $\alpha$ phases, $\kappa$ phases, and $\gamma$ phases. Tin was largely distributed in $\gamma$ phases in the form of solid solution.

The ratio of $\gamma$ phase among all the phases in metal structure was measured in the samples of castings made of alloys comprising $76.0 \mathrm{Cu}-3.0 \mathrm{Si}-0.08 \mathrm{P}$ with an addition of various amounts of tin. The castings were prepared by pouring molten material into a sand mold at $1100^{\circ} \mathrm{C}$.

Figure 7 shows the relationship between tin content and the $\gamma$ phase ratio. The higher the tin content was, the higher the $\gamma$ phase ratio was. There was a tendency that the $\gamma$ phase ratio increased almost linearly until tin content reached around 0.5 mass $\%$, then the increase saturated when tin content slightly exceeded 0.6 mass $\%$.

\subsection{Mechanical properties}

Figure 8 shows the relationship between zinc equivalent and elongation.

As the zinc equivalent became larger, elongation deteriorated. In addition, when compared at the same zinc equivalent level, the higher the tin content was, the worse the elongation was. Even so, all the test samples containing tin up to 0.6 mass \% showed elongation of $15 \%$ or more. Elongation is less affected by zinc equivalent when tin is added in the amount between 0.4 and 0.6 mass $\%$.

\subsection{Erosion-corrosion resistance}

Figures 9 and 10 show the results of the erosion-corrosion resistance tests in which $\mathrm{NaCl}$ solution and hypochlorite water were used as test solutions.

In the test with $\mathrm{NaCl}$ solution, the difference in weight re-

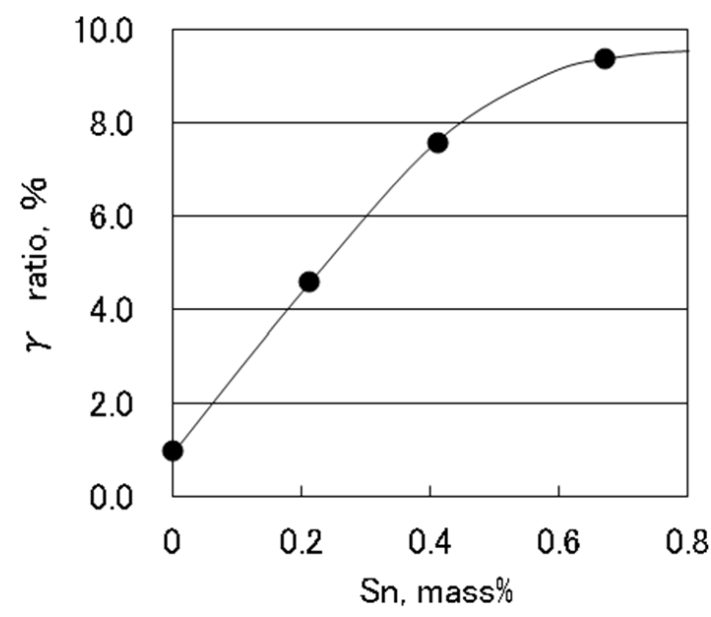

Fig. 7 Relationship between Sn content and $\gamma$ ratio.

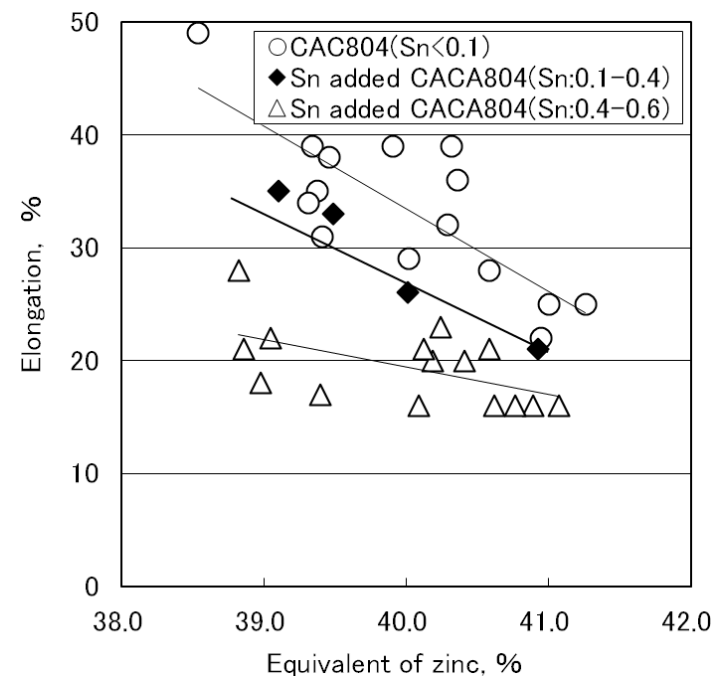

Fig. 8 Influence of zinc equivalent and Sn on elongation.

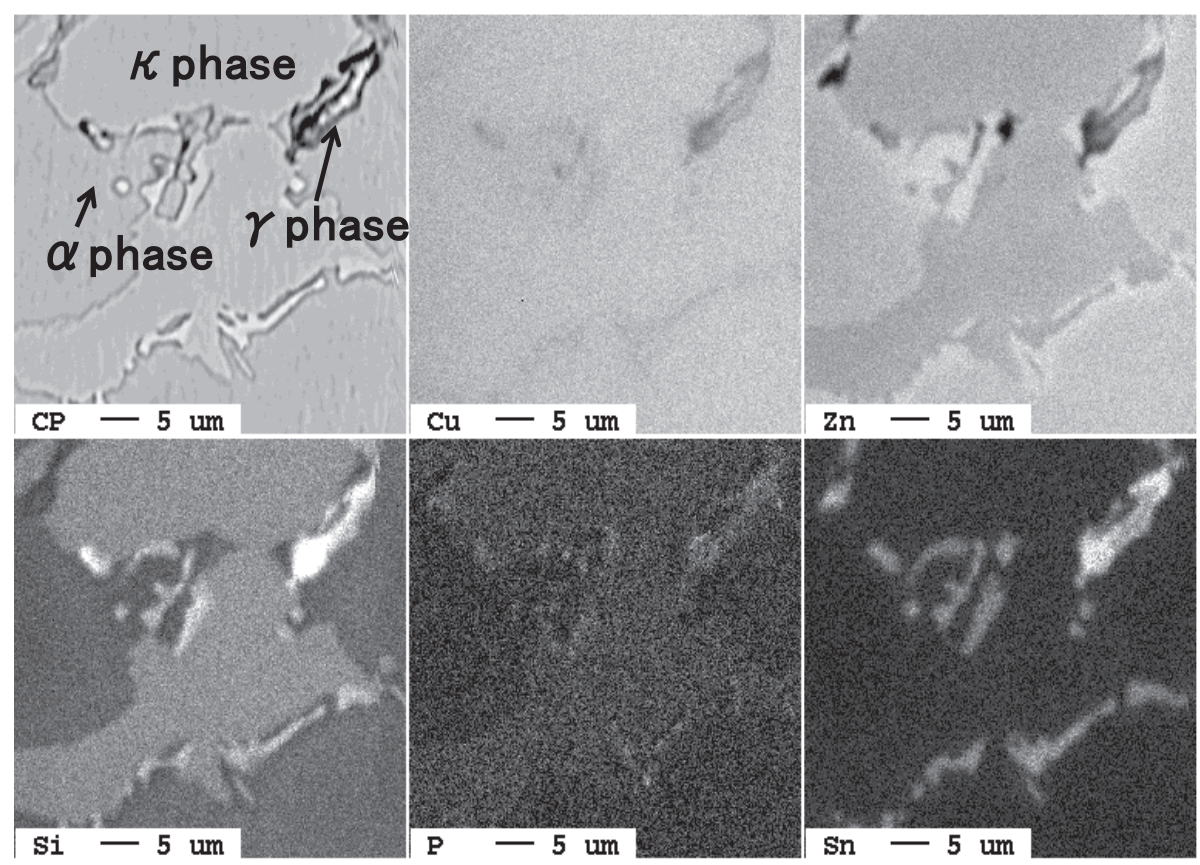

Fig. 6 Mapping of phases in 0.5 mass\% Sn-CAC 804. 


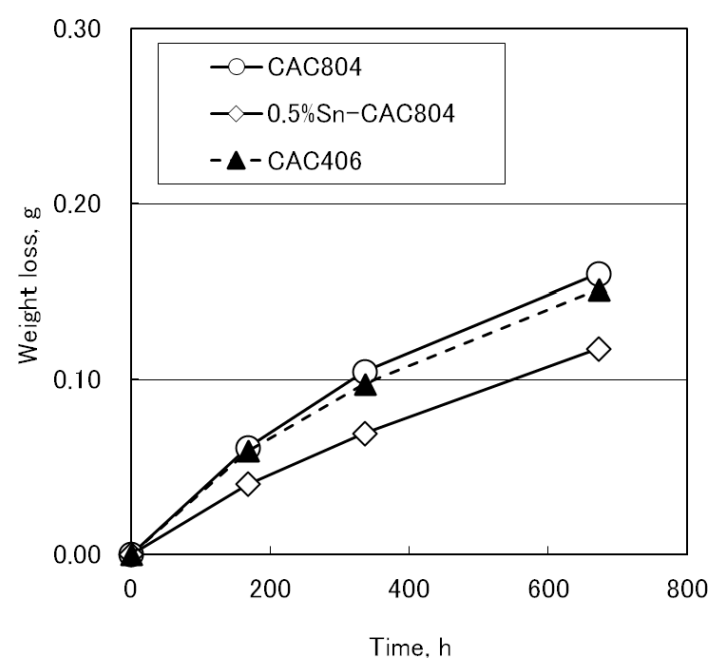

Fig. 9 Weight loss in jet-in-slit test with $3 \% \mathrm{NaCl}$ solution.

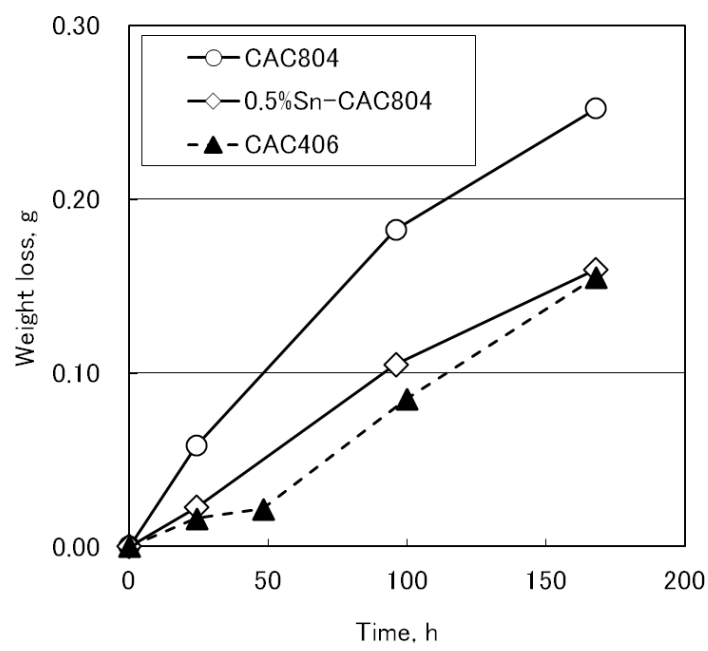

Fig. 10 Weight loss in jet-in-slit test with hypochlorite water.

duction between CAC804 and CAC406 was hardly found, and $0.5 \%$ Sn-CAC804 was the one that lost least weight. On the other hand, in hypochlorite water, all the tested alloys lost much more weight for the same duration of time, and CAC804 lost twice as much weight as CAC406 did. Weight reduction level of $0.5 \%$ Sn-CAC804 was about the same as that of CAC406. There is no standard method for testing erosion-corrosion resistance, and the results varies depending on the test solution used as shown in our test results. In addition, these are results of accelerated tests, and thus the correlation between the test results and actual erosion-corrosion resistance when used as water faucets and the like remains uncertain. Still, our tests did show that in these two kinds of test solutions, addition of tin to CAC804 had an effect of alleviating weight reduction in the alloy.

\section{Conclusions}

Our study has shown that addition of tin gives the following influence on the characteristics of CAC804.

(1) Solidus and liquidus temperatures both decrease, and the solidification temperature range broadens, though slightly.

(2) Castability does not get much affected, but by further adding zirconium to refine the metal structure, the shrinkage cavity defect in the finally solidified portion greatly reduces.

(3) $\gamma$ phase increases. Tin is largely distributed in $\gamma$ phases.

(4) Elongation deteriorates, but $15 \%$ or higher level of elongation can still be obtained if the amount of tin is 0.6 mass $\%$ or less.

(5) In the erosion-corrosion resistance testing by the jet-inslit test apparatus, weight reduction level in the tin-containing alloys is less than that in those free of tin even though the degree of such weight reduction alleviation effect of tin differs depending on the test solution.

\section{REFERENCES}

1) e.g. "S. 3874, To amend the Safe Drinking Water Act to reduce lead in drinking water.", USA Gov., (2010).

2) "Directive 2011/65/EU of the European parliament and of the council of 8 June 2011", Official Journal of the European Union, (2011).

3) "Directive 2000.53/EC of the European Parliament and of the Council on end-of-life vehicles", Official Journal of the European Union, (2000).

4) K. Oishi, T. Matsumoto and T. Okubo: Journal of the Japan Copper and Brass Research Association 39 (2000) 8-15.

5) Metals Data Book (4th ed.):The Japan Institute of Metals and Materials, (2004), 179.

6) K.Oishi, Patent Application No. PCT/JP 200.5/008662, (2005).

7) K. Oishi, Y. Goto, T. Yoshikawa, T. Oka, Y. Tsugawa, S. Tanaka and T. Matsumoto: Journal of Japan Institute of Copper 46 (2007) 289-293. 